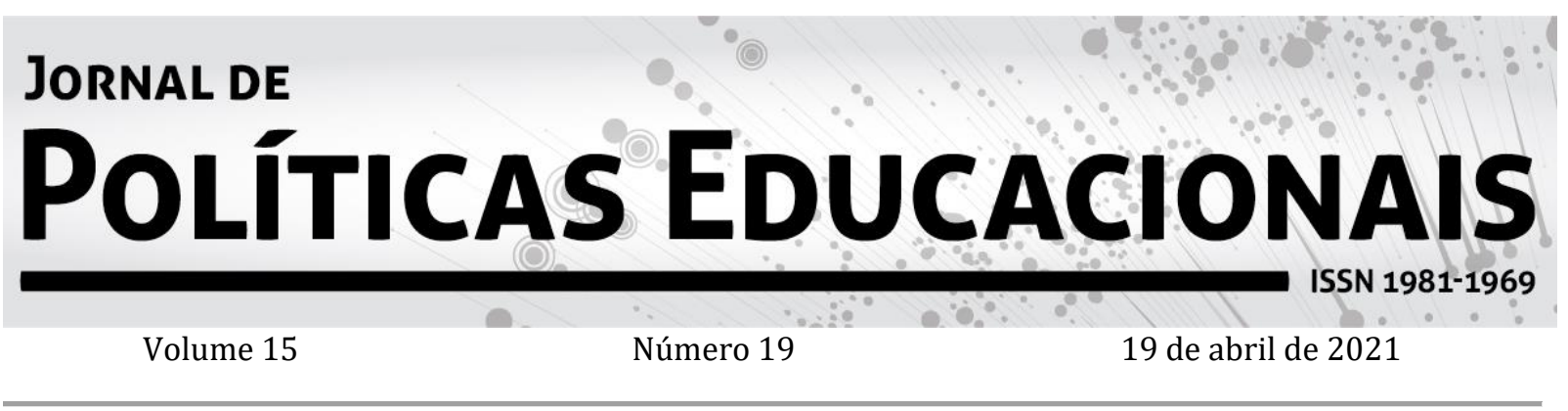

\title{
Base Nacional Comum Curricular e Currículo da Cidade: alinhamento total
}

\author{
Common National Curricular Base and City Curriculum of: total \\ alignment
}

\section{Currículo base común nacional y currículo de la ciudad: alineación total}

Pedro Xavier Russo Bonetto ${ }^{1}$

Citação: BONETTO, P. X. R. Base Nacional Comum Curricular e Currículo da Cidade: alinhamento total. Jornal de Políticas Educacionais. V. 15, n. 19. Abril de 2021.

http://10.5380/jpe.v15i0.78850

\begin{abstract}
Resumo
O artigo em questão examina o documento curricular do município de São Paulo, denominado Currículo da Cidade, e compara-o com a Base Nacional Comum Curricular. 0 método empreendido foi a análise de discurso em sua perspectiva foucaultiana. As verificações indicam que os discursos dos documentos estão absolutamente alinhados, quando não, iguais. Além disso, os documentos são produzidos no mesmo contexto social, ambos contaram com pouca participação efetiva dos professores e ilustram uma concepção de Educação Física tecnicista e acrítica.

Palavras-chave: Educação Física. Currículo. Políticas públicas. Base Nacional Comum Curricular. Currículo da Cidade.

\section{Abstract}

The article examines the curriculum document of the city of São Paulo, called the Currículo da Cidade, and compares it with the National Common Curricular Base. The method used was speech analysis in its Foucaultian perspective. The analyses indicate that the speeches described in the documents are absolutely aligned. In addition, the documents are produced in the same social context, they didn't have an effective engagement of teachers and illustrate a conception of technical and uncritical physical education.
\end{abstract}

\footnotetext{
${ }^{1}$ Doutorando em Educação na temática Educação e Ciências Sociais: Diferenças e Desigualdades (FE-USP). Professor da rede municipal de São Paulo e da Faculdade Flamingo nos cursos de Pedagogia e licenciatura em Educação Física. Membro do Grupo de Pesquisa em Educação Física Escolar da FE-USP. São Paulo, SP. Brasil. Orcid: https://orcid.org/0000-0002-3194-1423. E-mail: pedro.bonetto@grupoflamingo.com
} 
Keywords: Physical Education. Curriculum. Public policies. National Common Curricular Base. City Curriculum.

\section{Resumen}

El artículo analiza el documento curricular del municipio de São Paulo, denominado Currículo da Cidade, y lo compara con la Base Nacional Común Curricular. El método emprendido fue el análisis de discurso en su perspectiva foucaultiana. Los análises de los documentos se producen en el mismo contexto social, ambos contaron con poca participación efectiva de los profesores e ilustran una concepción de Educación Física tecnicista y acrítica.

Palabras clave: Educación Física. Currículo. Políticas públicas. Base Nacional Común Curricular. Currículo de la Ciudad.

\section{Introdução}

O ano é 2017, no âmbito nacional, ainda no mês de abril, o Ministério da Educação e Cultura (MEC) entrega uma quarta versão da Base Nacional Comum Curricular (BNCC) para o Conselho Nacional de Educação (CNE). Em dezembro, por meio da Resolução CNE/CP no 2, o CNE aprova o documento que, em seguida, é homologado pelo ministro da Educação, na época, Mendonça Filho, em cerimônia no Palácio do Planalto.

Na ocasião, por meio de um vídeo institucional do Ministério da Educação, o ministro chama de "dia histórico" e complementa dizendo que o Brasil terá sua primeira Base Nacional Comum Curricular, alinhando-se, consequentemente, aos melhores e mais qualificados sistemas educacionais do mundo.

Isso significa que um aluno do Piauí terá acesso ao mesmo aprendizado que o aluno de São Paulo, do Rio Grande do Sul, do Amazonas ou de Pernambuco. A base é um grande passo para diminuir desigualdades educacionais e promover a qualidade das aprendizagens (MENDONÇA FILHO, 2017, 0 min. $30 \mathrm{~s}^{2}$ ).

José Mendonça Filho destaca também que, a partir da homologação da BNCC, as redes de ensino públicas e particulares passam a ter uma referência nacional obrigatória para elaboração de seus currículos. Continuando, define que a Base Curricular é "inovadora, democrática e plural" e que o documento está sendo entregue aos brasileiros "sem ideologia de gênero, mas respeitando as diferenças e os Direitos Humanos". Se não bastasse, o ministro afirma que a BNCC homologada foi aprovada pelo Conselho Nacional

${ }^{2}$ Disponível em: https://www.youtube.com/watch?v=CouiSat5o 8. Acesso em: 2 jul. 2020. 
de Educação (CNE) após três anos de discussão com educadores, especialistas e a sociedade.

Na prática, o MEC, a partir de um novo ministro empossado, Rossieli Soares da Silva, institui o Programa de Apoio à Implementação da Base Nacional Comum Curricular (ProBNCC) e o "Dia D", dia nacional de discussão sobre a BNCC (já com a etapa do Ensino Médio), em que professores, gestores e técnicos da educação, teoricamente, debateram e preencheram um formulário on-line sugerindo melhorias no documento. Em 14 de dezembro de 2018, o ministro Rossieli Soares da Silva homologa a última versão do documento já com a etapa do Ensino Médio³.

Retornando para 2017, no âmbito do município de São Paulo, após eleito no primeiro turno, João Dória nomeia para secretário municipal de Educação Alexandre Alves Schneider. No mesmo ano, anuncia-se a elaboração de um novo documento curricular para o município. Em março de 2017, o documento começa a ser preparado com a realização de um seminário municipal. Em agosto, assim como aconteceu com a BNCC, é criada uma atividade de consulta on-line para professores e professoras das escolas do município. Em dezembro, sua versão é finalizada e o documento é publicado.

De acordo com a Secretaria Municipal de Educação do Município de São Paulo (SME-SP), o novo currículo vai formar cidadãos globais, salientando-se que todos (governos, agências da Organizações das Nações Unidas - ONU, sociedade civil organizada, setor privado e cada cidadão de cada país) têm responsabilidades para que o mundo consiga atingir os objetivos de desenvolvimento sustentável (ODS), adotados em 2015 pela Assembleia Geral da ONU.

Após a publicação do documento, para a SME-SP o desafio seria a implementação do novo currículo de São Paulo. Para tanto, os membros das Diretorias Regionais de Educação (DRE) foram formados para que eles mesmos consigam repassar as informações para os professores das escolas de suas regionais. Os professores, por sua vez, devem ser capacitados para conseguirem visualizar os desafios da escola e buscar as soluções com os alunos.

Já o segredo para fazer com que o processo de construção e implementação de um currículo seja exitoso e realmente incorporado pelas escolas é, segundo Wagner Palanch, diretor de currículo da SME, focar na territorialidade e na identidade local. "O currículo de São Paulo

\footnotetext{
${ }^{3}$ Vale destacar que a produção de uma base comum para o currículo é pensada pelo Ministério da Educação (MEC) no Brasil, desde 2009, com o Programa Currículo em Movimento.
} 
tem a cara da cidade", afirma o diretor da SME, Wagner Palanch. A ideia, portanto, é apontar caminhos para a construção de um currículo que traga essa identidade, e não simplesmente replicar o currículo de outras localidades em outros municípios ou em outros estados ${ }^{4}$.

Na apresentação do documento, os autores afirmam que o Currículo da Cidade "foi elaborado a muitas mãos pelos profissionais de nossa Rede, resultado de um trabalho dialógico e colaborativo, que buscou integrar as experiências, práticas e culturas escolares já existentes na história desta Rede" (p. 7).

Considerando esta breve contextualização e reconhecendo a importância desses documentos curriculares, um no âmbito nacional, outro da capital do estado de São Paulo, o presente artigo tem como objetivo promover uma análise dos discursos sobre as concepções de Educação Física, objetivos do componente, concepções de aprendizagem e conhecimento, explicitados nos textos da BNCC (2018) e do Currículo da Cidade (2017).

Portanto, o intuito é desenvolver uma análise de discurso (AD) partir de uma perspectiva foucaultiana (BRANDÃO, 2004; FISCHER, 1995; 2001; RODRIGUES; MELLO, 2020). Importante ressalvar que tal concepção não se constitui exatamente como a de uma ferramenta metodológica ou interpretativa. É mais uma concepção de linguagem, como acontecimentos, a qual, por sua vez, a partir de determinados contextos, saberes e domínios, produz regimes discursivos que se instituem como verdade. Assim, Fischer (1995) assevera que os objetos de um discurso podem prestar-se a inúmeras análises, pois os jogos de relações, dentro e fora dos discursos, são também inúmeros. Ao circunscrever sua região de trabalho, o analista tem condições de investigar as regras de aparecimento de um objeto, as quais permitirão conferir um tipo de unidade ao discurso.

Embora se apoie nos conceitos da linguística, o interesse da AD recai principalmente sobre os textos cujos enunciados seriam restringidos por um forte esquema institucional; também sobre aqueles materiais linguísticos em que se inscrevem e se cristalizam embates sociais significativos; finalmente, sobre os textos que se afirmam por constituir um espaço próprio, no exterior de um interdiscurso limitado (FISCHER, 1995, p. 22).

Assim, interessa-nos também relacionar os discursos pedagógicos dos referidos documentos curriculares, identificando suas similitudes de enunciação, seus contextos e

\footnotetext{
4 Disponível em: https://nacoesunidas.org/curriculo-escolar-de-sao-paulo-aborda-objetivos-dedesenvolvimento-sustentavel/. Acesso em: 5 jul. 2020.
} 
intencionalidades, bem como as relações de saber-poder que constituem e estabelecem os discursos presentes nos textos.

\section{Método}

$\mathrm{Na}$ tentativa de analisar as concepções de Educação Física, objetivos do componente, concepções de aprendizagem e conhecimentos explicitados nos documentos curriculares, BNCC (2018) e do Currículo da Cidade (2017), empreendemos uma análise de discurso em uma perspectiva foucaultiana.

Brandão (2004), amparada pela perspectiva foucaultiana, sustenta que o discurso seria concebido como uma família de enunciados pertencentes a uma mesma formação discursiva. Segundo a autora, é a que diz respeito à existência de um domínio, a associação de um enunciado a um conjunto de enunciados, que, inspirada em Foucault, afirma que não existe um enunciado isolado, ou seja, em um enunciado pode estar presente um ou mais enunciados de outros discursos.

Outrossim, Fischer (2001) escreve que, para analisar os discursos, segundo a perspectiva de Foucault, precisamos recusar as explicações unívocas, as fáceis interpretações e a busca do sentido último ou oculto das coisas. Por essa razão, é preciso ficar no nível de existência das palavras, das coisas ditas, trabalhar arduamente com o próprio discurso, deixando-o aparecer na complexidade que lhe é peculiar. Além disso, defende-se a ideia do discurso como uma produção de sentidos, em um determinado contexto social, histórico e em certas condições que são imanentes, provisórias, arbitrárias e estreitamente associadas com relações de poder de seu tempo.

$\mathrm{Na}$ perspectiva foucaultiana, as relações de poder não são essencialmente negativas, visto que não apenas proíbem, oprimem, impedem, mas também produzem, criam, inventam, recortam as coisas, o mundo, os homens e dão visibilidade. Dessa maneira, o poder está intimamente relacionado com as questões de saber.

Fischer (1995, p. 22) afirma que "discurso e poder são inseparáveis. 0 discurso, esse 'bem positivo', tem suas regras de aparecimento, tem suas condições de apropriação e coloca, desde o início, a questão do poder. Ele é, por natureza, e sempre, objeto de uma luta política”.

[...] o poder possui uma eficácia produtiva, uma riqueza estratégica, uma positividade. 0 que faz com que o poder se mantenha e que seja aceito é 
simplesmente que ele não pesa só como uma força que diz não, mas que de fato ele permeia, produz coisas, induz ao prazer, forma saber, produz discurso. Deve-se considerá-lo como uma rede produtiva que atravessa todo o corpo social muito mais do que uma instância negativa que tem por função reprimir (FOUCAULT, 2012, p. 44-45).

Portanto, busca-se analisar os discursos explicitados no texto e aqueles que falam sobre o texto. Não há nada oculto, nada fora do texto e os discursos se envolvem em relações de poder com a produção de saberes. Para o filósofo francês, saber é poder. Assim, estabelece-se a famosa relação de "saber-poder", cuja questão principal não é mais "O que diz isso?" ou "0 que isso quer dizer?", mas "Sob quais poderes esse saber se constituiu?", “Como se constituiu esse saber, e não outro?", "Quais as estratégias discursivas empregadas na instauração desses discursos?".

Para Fischer (2001), nossos atos de fala se inscrevem no interior de algumas formações discursivas e de acordo com certo regime de verdade, o que significa que estamos obedecendo a um conjunto de regras dadas historicamente e afirmando verdades de um tempo.

Cada sociedade tem seu regime de verdade, sua "política geral de verdade", isto é, os tipos de discurso que ela aceita e faz funcionar como Verdadeiros; os mecanismos e as instâncias que permitem distinguir os enunciados verdadeiros e os falsos, a maneira como se sancionam uns e outros; as técnicas e procedimentos que são valorizados para a obtenção da verdade; o estatuto daqueles que têm a função de dizer o que funciona como verdadeiro (FOUCAULT, 2011, p. 213).

Ainda de acordo com Fischer (2001), na verdade, tudo é prática em Foucault. E tudo está imerso em relações de poder e saber, que se implicam mutuamente, enunciados e visibilidades, textos e instituições, falar e ver constituem práticas sociais amarradas às relações de poder, que as supõem e as atualizam.

\section{Análise dos discursos}

Comecemos assinalando que os procedimentos de análise e o objeto de estudo têm forte dependência do que chamamos de condições de produção. As condições de produção caracterizam o discurso, pois foram elas que possibilitaram a imanência dos discursos analisados. Assim, a construção de um discurso pelo sujeito depende de suas condições de produção. Logo, seria esperado que entre os documentos, BNCC (2018) e Currículo da 
Cidade (2017), houvesse semelhanças e relações de dialogicidade, justamente porque são frutos do mesmo tempo, dos mesmos contextos políticos, econômicos e sociais.

0 fato de que os enunciados se constroem sob determinadas circunstâncias bem concretas leva-nos a discutir mais exaustivamente esse conceito fundamental da $\mathrm{AD}$ : as condições de produção de um discurso. O contexto histórico-social, o lugar de onde falam os interlocutores, a imagem que cada um faz do outro - tudo isso deve ser considerado na análise (FISCHER, 1995, p. 31).

Em especial, chama-nos atenção a ruptura existente entre a segunda e a terceira versão na BNCC (2015-20165), bem como a ruptura do Currículo da Cidade (2017) em relação ao documento Direitos de Aprendizagem (SÃO PAULO, 2016) produzido e publicado apenas um ano antes do atual. Que pressa seria essa de interditar e substituir o que estava sendo elaborado há tão pouco tempo? Será que o contexto de impeachment e a criminalização das políticas consideradas à esquerda aceleraram o processo? A segunda versão da BNCC em gestão ainda pelo MEC da Presidente Dilma Rousseff e os Direitos de Aprendizagem (2016), gestados durante o mandato do ex-prefeito Fernando Haddad, precisavam, com tudo o que vinha do referido partido, ser interrompidos e substituídos? Isso fica evidente a partir da fala do ministro Mendonça Filho, mas não tão explícito no caso do documento oficial do município.

Outro elemento importante da análise de discurso refere-se aos sujeitos que enunciam e os sujeitos que são enunciados pelos documentos.

Quadro 1. Comparação entre os enunciadores (elaboradores) dos textos

\begin{tabular}{|l|l|}
\hline \multicolumn{1}{|c|}{ Currículo da Cidade } & \multicolumn{1}{c|}{ BNCC } \\
\hline $\begin{array}{l}\text { Secretaria Municipal de Educação (SME- } \\
\text { SP) }\end{array}$ & Ministério da Educação (MEC) \\
\hline $\begin{array}{l}\text { Assessoria da Educação Física: Prof. Dra. } \\
\text { Suraya Cristina Darido da Cunha. }\end{array}$ & $\begin{array}{l}\text { Comissão de Especialistas da Base Nacional } \\
\text { Comum: Prof. Dra. Suraya Cristina Darido } \\
\text { da Cunha (Educação Física). }\end{array}$ \\
\hline $\begin{array}{l}\text { Equipe técnica composta apenas 20 } \\
\text { professores/as, indicados/as pelas 13 } \\
\text { diretorias regionais6. }\end{array}$ & $\begin{array}{l}\text { Conselho Nacional de Secretários de } \\
\text { Educação (CONSED). } \\
\text { União Nacional dos Dirigentes Municipais } \\
\text { de Educação (UNDIME). }\end{array}$ \\
\hline $\begin{array}{l}\text { "Para dar conta dessa pluralidade, o } \\
\begin{array}{l}\text { Currículo da Cidade foi construído a partir } \\
\text { da escuta e da colaboração de estudantes, }\end{array}\end{array}$ & $\begin{array}{l}\text { Elaborada por especialistas de todas as } \\
\text { áreas do conhecimento, a Base é um } \\
\text { documento completo e contemporâneo, }\end{array}$ \\
\hline
\end{tabular}

\footnotetext{
${ }^{5}$ Disponível em http://basenacionalcomum.mec.gov.br/historico. Acesso em: 5 jul. 2020.

${ }^{6} \mathrm{~A}$ título de comparação, no documento antecessor foram 51 professores que participaram da elaboração, sem contar os professores designados nas próprias DREs.
} 


\begin{tabular}{|l|l|}
\hline $\begin{array}{l}\text { professores e gestores da Rede Municipal } \\
\text { de Ensino (SÃO PAULO, 2017, p. 17). }\end{array}$ & $\begin{array}{l}\text { que corresponde às demandas do } \\
\text { estudante desta época, preparando-o para } \\
\text { o futuro. Concluída após amplos debates } \\
\text { com a sociedade e os educadores do Brasil } \\
{[. .] \text { (BNCC, 2018, p. 5). }}\end{array}$ \\
\hline Consulta on-line. & Consulta dos professores on-line (Dia “D”). \\
\hline
\end{tabular}

Fonte: Elaborado pelo autor (2021)

Importante realçar que ambos os materiais, por reduzidas que tenham sido as participações nos fóruns decisivos de produção dos textos, obviamente não são produções de um órgão ou sujeito autônomo e centrado. Não contemplamos o aspecto ideológico, muito menos de um Ser consciente e potente de suas intencionalidades, portanto capaz de gerir as práticas pedagógicas de professores e professoras de um município inteiro, quiçá do Brasil. Certamente, outras instâncias, campos enunciativos, grupos sociais, afetaram os discursos lá presentes. Há de considerar a ampla participação em instâncias anteriores, na BNCC, nas versões anteriores e no município de São Paulo, durante a produção dos últimos documentos. Há de se levar em conta a presença (de poucos) de grupos diferentes nos textos da versão final. Por fim, o reconhecimento daquilo que estava permeando a área, seus saberes já instituídos em fóruns e tempos anteriores.

Todavia, é importante observar: Quem são os enunciadores? De onde eles/elas falam? Ministério da Educação (MEC) e Secretaria Municipal de São Paulo. Tudo indica que há um jogo entre os enunciadores-autoridades, ou seja, "voz oficial", "voz da lei", "voz do governo", "aqueles que auxiliam", "controlam", "orientam", os quais avalizam os enunciados constitutivos de uma "boa aula de Educação Física”, "bons conteúdos", "boas práticas curriculares". Outrossim, sobre os sujeitos dos quais esses textos falam, no caso, os documentos curriculares BNCC e Currículo da Cidade, a quem se referem?

Quadro 2. Sujeitos que são enunciados pelos textos (público-alvo)

\begin{tabular}{|l|l|}
\hline \multicolumn{1}{|c|}{ Currículo da Cidade } & \multicolumn{1}{|c|}{ BNCC } \\
\hline Nosso propósito é que o Currículo da & Nesse sentido, espera-se que a BNCC ajude \\
Cidade oriente o trabalho na escola e, mais & a superar a fragmentação das políticas \\
especificamente, na sala de aula. Para isso, & educacionais, enseje o fortalecimento do \\
faz parte de nossas ações de implantação a & regime de colaboração entre as três esferas \\
\hline
\end{tabular}

\footnotetext{
${ }^{7}$ No mês de agosto, essa versão foi colocada para consulta das equipes gestora e docente, supervisores e formadores das DREs, no Sistema de Gestão Pedagógica (SGP), totalizando mais de 9.000 leituras e mais de 2.550 contribuições analisadas pelas equipes técnicas do Núcleo Técnico de Currículo (NTC) e Divisão de Ensino Fundamental e Médio (DIEFEM) (SÃO PAULO, 2017, p. 13).
} 
produção de um volume com Orientações Didáticas e a de Materiais Didáticos, que complementam as discussões deste currículo e apoiam as atividades diárias com os estudantes. A formação continuada dos profissionais da Rede também integra essas ações, pois é condição para o salto qualitativo na aprendizagem dos nossos estudantes, premissa em que este documento está fundamentado (p. 7).

A SME irá propor projetos de formação continuada juntamente com as escolas, priorizando processos de desenvolvimento profissional centrados na prática letiva de cunho colaborativo e reflexivo, a fim de que os professores tenham condições de implementar o novo currículo considerando seu contexto escolar (p. 49). de governo e seja balizadora da qualidade da educação. Assim, para além da garantia de acesso e permanência na escola, é necessário que sistemas, redes e escolas garantam um patamar comum de aprendizagens a todos os estudantes, tarefa para a qual a BNCC é instrumento fundamental (p. 8).

Fonte: Elaborado pelo autor (2021)

- Construir e aplicar procedimentos de avaliação formativa de processo ou de resultado que levem em conta os contextos e as condições de aprendizagem, tomando tais registros como referência para melhorar o desempenho da escola, dos professores e dos alunos.

- Criar e disponibilizar materiais de orientação para os professores, bem como manter processos permanentes de formação docente que possibilitem contínuo aperfeiçoamento dos processos de ensino e aprendizagem.

- Manter processos contínuos de aprendizagem sobre gestão pedagógica e curricular para os demais educadores, no âmbito das escolas e sistemas de ensino (p. 17).

Aqui, ambos os documentos se dirigem para enunciadores-reprodutores, inseridos na trama discursiva da "melhoria da educação básica", "salto qualitativo", "desenvolvimento profissional" e "melhorar o desempenho da escola". Todos elementos relacionados com a necessidade de cursos de formação continuada de professores. Ainda que seja dura a acusação, os textos colocam a autonomia das redes de ensino e a capacidade profissional e intelectual dos docentes sob suspeição. Tratamos, aqui, com os professores "desorientados", com "formação ultrapassada", "que precisam fazer dessa forma”, “que não sabem dar aulas assim”, portanto, "que fazem errado”, possivelmente "malformados".

Dessarte, corroboramos a análise de Rufino e Souza Neto (2016) de que a BNCC pode se desenvolver a partir de um cenário utilitarista e meramente aplicacionista. Apoiados nos estudos de Maurice Tardif, os autores asseveram que essa perspectiva desconsidera o trabalho docente como núcleo gerador de sentidos e significados da 
profissão, estando em desacordo com os processos que buscam legitimar a profissionalização do ensino.

Outro elemento que nos chama atenção é o discurso de "patamar comum de aprendizagens" ou "aprendizagens essenciais", pois fica nítido que o texto procura se justificar pautado pela tese de "unidade", "igualdade" e "desfragmentação" das verdades sobre a Educação.

No Brasil, um país caracterizado pela autonomia dos entes federados, acentuada diversidade cultural e profundas desigualdades sociais, os sistemas e redes de ensino devem construir currículos, e as escolas precisam elaborar propostas pedagógicas que considerem as necessidades, as possibilidades e os interesses dos estudantes, assim como suas identidades linguísticas, étnicas e culturais (BRASIL, 2018, p. $15)$.

Assim, quando a BNCC coloca a "autonomia dos entes federados", a "acentuada diversidade cultural", ao lado das "profundas desigualdades sociais", estabelece-se uma relação de causalidade entre os dois primeiros elementos e a desigualdade, criando a demanda por currículos normativos.

Continuando, é importante reconhecer que os dois documentos se apoiam explicitamente, trata-se de um alinhamento, tal como deve ser uma proposta nacional e uma municipal, buscando assim o chamado pacto interfederativo.

Quadro 3. Enunciados que demonstram o alinhamento entre os documentos

\begin{tabular}{|c|c|}
\hline Currículo da Cidade & BNCC \\
\hline $\begin{array}{l}\text { O Currículo da Cidade busca alinhar as } \\
\text { orientações curriculares do Município de } \\
\text { São Paulo ao processo de construção da } \\
\text { Base Nacional Comum Curricular (BNCC), } \\
\text { documento que define as aprendizagens } \\
\text { essenciais a que todos os estudantes } \\
\text { brasileiros têm direito ao longo da } \\
\text { Educação Básica. A BNCC estrutura-se com } \\
\text { foco em conhecimentos, habilidades, } \\
\text { atitudes e valores para promover o } \\
\text { desenvolvimento integral dos estudantes e } \\
\text { a sua atuação na sociedade (p. 10). }\end{array}$ & $\begin{array}{l}\text { Legitimada pelo pacto interfederativo, nos } \\
\text { termos da Lei no } 13.005 / 2014 \text {, que } \\
\text { promulgou o PNE, a BNCC depende do } \\
\text { adequado funcionamento do regime de } \\
\text { colaboração para alcançar seus objetivos. } \\
\text { Sua formulação, sob coordenação do MEC, } \\
\text { contou com a participação dos Estados do } \\
\text { Distrito Federal e dos Municípios, depois de } \\
\text { ampla consulta à comunidade educacional } \\
\text { e à sociedade, conforme consta da } \\
\text { apresentação do presente documento (p. } \\
\text { 20). }\end{array}$ \\
\hline $\begin{array}{l}\text { Nos objetos de conhecimento, foram } \\
\text { utilizadas em algumas práticas corporais as } \\
\text { categorias apontadas pela BNCC (2017). No } \\
\text { cotidiano da escola, em cada plano de } \\
\text { ensino e de acordo com sua realidade } \\
\text { territorial, podem-se construir outras }\end{array}$ & $\begin{array}{l}\text { Com a homologação da BNCC, as redes de } \\
\text { ensino e escolas particulares terão diante } \\
\text { de si a tarefa de construir currículos, com } \\
\text { base nas aprendizagens essenciais } \\
\text { estabelecidas na BNCC, passando, assim, do } \\
\text { plano normativo propositivo para o plano }\end{array}$ \\
\hline
\end{tabular}


relações e outras compreensões que da ação e da gestão curricular que envolve ampliem o entendimento do fenômeno da cultura corporal (NOTA DE RODAPÉ, p. 75). todo o conjunto de decisões e ações definidoras do currículo e de sua dinâmica (p. 20).

Fonte: Elaborado pelo autor (2021)

Fica evidente, então, que a BNCC foi produzida num contexto de inspirar e orientar os demais currículos, dos estados e municípios, mas torna-se duvidoso o grau de autonomia que tais redes poderão usufruir, uma vez que, além de "implementar" o texto da BNCC, descreve uma ação de monitoramento: "Por se constituir em uma política nacional, a implementação da BNCC requer, ainda, o monitoramento pelo MEC em colaboração com os organismos nacionais da área - CNE, Consed e Undime” (p. 21).

Em busca da especificidade das redes de ensino, bem como da garantia de uma certa autonomia no trabalho dos professores, ambos os textos chamam atenção para a possibilidade de construção de currículos locais, com autonomia para organizar seus percursos formativos a partir de suas próprias realidades.

Quadro 4. Enunciados que indicam a possibilidade de reconstrução dos discursos presentes nos documentos.

\begin{tabular}{|c|c|}
\hline Currículo da Cidade & BNCC \\
\hline $\begin{array}{l}\text { [...] Sua implementação acontece por meio } \\
\text { da construção de currículos locais, de } \\
\text { responsabilidade das redes de ensino e } \\
\text { escolas, que têm autonomia para organizar } \\
\text { seus percursos formativos a partir da sua } \\
\text { própria realidade, incorporando as } \\
\text { diversidades regionais e subsidiando a } \\
\text { forma como as aprendizagens serão } \\
\text { desenvolvidas em cada contexto escolar (p. } \\
\text { 10). }\end{array}$ & $\begin{array}{l}\text { Por fim, cabe aos sistemas e redes de } \\
\text { ensino, assim como às escolas, em suas } \\
\text { respectivas esferas de autonomia e } \\
\text { competência, incorporar aos currículos eàs } \\
\text { propostas pedagógicas a abordagem de } \\
\text { temas contemporâneos que afetam a vida } \\
\text { humana em escala local, regional e global, } \\
\text { preferencialmente de forma transversal e } \\
\text { integradora (p. 19). }\end{array}$ \\
\hline $\begin{array}{l}\text { Cabe destacar ainda que os objetivos de } \\
\text { aprendizagem e desenvolvimento } \\
\text { apresentam uma numeração que tem como } \\
\text { propósito a localização. Não se trata, em } \\
\text { hipótese alguma, uma sequência a ser } \\
\text { seguida, nem um pré-estágio ou um pré- } \\
\text { requisito para trabalhar com um objetivo e } \\
\text { depois outro, já que a dinâmica das aulas, o } \\
\text { planejamento do professor e sua leitura } \\
\text { aguçada pela avaliação é que determinarão } \\
\text { quantos e quais objetivos serão } \\
\text { trabalhados (p. 74). }\end{array}$ & \\
\hline
\end{tabular}

Fonte: Elaborado pelo autor (2021) 
Avançando na materialidade dos discursos (técnicas, práticas, relações sociais, conhecimento), Fischer (1995) descreve que o sentido também não é dado a priori, uma vez que as palavras só significam no interior de cada formação discursiva, isto é, no jogo de relações com outras palavras, expressões ou construções dessa mesma formação. Agora, é o momento de desmembrar, identificar e agrupar os elementos efetivamente citados. Por esse motivo, tentamos elaborar uma espécie de mapa do discurso em questão, desenhando seus contornos e intersecções do interior do campo discursivo dos documentos curriculares oficiais.

No que tange às concepções de Educação Física, os documentos demonstram novamente um forte alinhamento.

Quadro 5. A concepção de Educação Física enunciada pelos documentos e organização dos eixos/unidades temáticas

\begin{tabular}{|c|c|}
\hline Currículo da Cidade & BNCC \\
\hline $\begin{array}{l}\text { Diante desse contexto, a Educação Física } \\
\text { como linguagem valoriza e reconhece essa } \\
\text { diversidade e busca criar um ambiente } \\
\text { propício para que as diferentes narrativas } \\
\text { possam se manifestar a partir de suas } \\
\text { próprias culturas. Tratar a cultura corporal } \\
\text { dessa maneira não é valorizar o que no } \\
\text { senso comum se diz ser "teoria" em } \\
\text { detrimento da prática. Pelo contrário, é } \\
\text { compreender que a vivência (prática } \\
\text { refletida) só é ampla e integral se atuamos } \\
\text { sobre o "saber fazer", atribuindo, } \\
\text { problematizando e produzindo } \\
\text { significados. (p. 68) }\end{array}$ & $\begin{array}{l}\text { Esse modo de entender a Educação Física } \\
\text { permite articulá-la à área de Linguagens, } \\
\text { resguardadas as singularidades de cada um } \\
\text { dos seus componentes, conforme } \\
\text { reafirmado nas Diretrizes Curriculares } \\
\text { Nacionais para o Ensino Fundamental de } \\
\text { Nove Anos (Resolução CNE/CEB no } 7 / 2010 \\
\text { (p. 214). }\end{array}$ \\
\hline $\begin{array}{l}\text { Em relação aos objetos de conhecimento, a } \\
\text { organização ao longo dos ciclos teve a } \\
\text { preocupação em contemplar diferentes } \\
\text { contextos. No Ciclo de Alfabetização, a } \\
\text { partir do contexto familiar/comunitário } \\
\text { [...]. No Ciclo Interdisciplinar, os objetos de } \\
\text { conhecimento são tematizados a partir do } \\
\text { contexto regional e nacional. [...] No Ciclo } \\
\text { Autoral, apresentam-se os objetos de } \\
\text { conhecimento no contexto mundial e } \\
\text { digital (p. 74). }\end{array}$ & $\begin{array}{l}\mathrm{Na} \text { BNCC, as unidades temáticas de } \\
\text { Brincadeiras e jogos, Danças e Lutas estão } \\
\text { organizadas em objetos de conhecimento } \\
\text { conforme a ocorrência social dessas } \\
\text { práticas corporais, das esferas sociais mais } \\
\text { familiares (localidade e região) às menos } \\
\text { familiares (esferas nacional e mundial). Em } \\
\text { Ginásticas, a organização dos objetos de } \\
\text { conhecimento se dá com base na } \\
\text { diversidade dessas práticas e nas suas } \\
\text { características. Em Esportes, a abordagem } \\
\text { recai sobre a sua tipologia (modelo de } \\
\text { classificação), enquanto Práticas corporais } \\
\text { de aventura se estrutura nas vertentes } \\
\text { urbana e na natureza (p. 219). }\end{array}$ \\
\hline
\end{tabular}




\begin{tabular}{|l|l|}
\hline $\begin{array}{l}\text { Eixos Temáticos: jogos e brincadeiras, } \\
\text { danças, lutas, ginásticas, esportes e práticas } \\
\text { corporais de aventuras. }\end{array}$ & $\begin{array}{l}\text { Unidades Temáticas: jogos e brincadeiras, } \\
\text { danças, lutas, ginásticas, esportes e práticas } \\
\text { corporais de aventura. }\end{array}$ \\
\hline $\begin{array}{l}\text { Jogos e Brincadeiras (contexto familiar e } \\
\text { comunitário, regionais e populares do } \\
\text { Brasil, do mundo e digitais). }\end{array}$ & $\begin{array}{l}\text { Jogos e Brincadeiras (do contexto } \\
\text { comunitário e regional, populares do Brasil } \\
\text { e do mundo, de matriz indígena e africana e } \\
\text { jogos eletrônicos). }\end{array}$ \\
\hline $\begin{array}{l}\text { Esporte (marca; precisão; invasão; campo } \\
\text { e taco, rede e parede; combate e técnico- } \\
\text { combinatório). }\end{array}$ & $\begin{array}{l}\text { Esporte (marca; precisão; invasão; campo } \\
\text { e taco, rede e parede; combate e técnico- } \\
\text { combinatório). }\end{array}$ \\
\hline $\begin{array}{l}\text { Ginásticas (Geral, práticas corporais } \\
\text { circenses e ginástica de condicionamento, } \\
\text { ginástica de consciência corporal). }\end{array}$ & $\begin{array}{l}\text { Ginásticas (Geral, de condicionamento } \\
\text { físico e ginástica de consciência corporal). }\end{array}$ \\
\hline $\begin{array}{l}\text { Danças (contexto familiar, comunitário, } \\
\text { regional e midiático, do Brasil, urbanas do } \\
\text { Brasil e do mundo). }\end{array}$ & $\begin{array}{l}\text { Danças (contexto comunitário e regional } \\
\text { do Brasil e do mundo Danças de matriz } \\
\text { indígena e africana, urbanas e de salão). }\end{array}$ \\
\hline $\begin{array}{l}\text { Lutas djogos de oposição, de oposição do do } \\
\text { contexto familiar e comunitário, do Brasil, } \\
\text { curta, média, longa e mista distância). }\end{array}$ & $\begin{array}{l}\text { Lutas (Lutas do contexto comunitário e } \\
\text { regional, lutas de matriz indígena e } \\
\text { africana, do Brasil e do Mundo). }\end{array}$ \\
\hline $\begin{array}{l}\text { Práticas corporais de aventuras } \\
\text { (urbanas e na natureza). }\end{array}$ & $\begin{array}{l}\text { Práticas corporais de aventuras } \\
\text { (urbanas e na natureza). }\end{array}$ \\
\hline
\end{tabular}

Fonte: Elaborado pelo autor (2021)

Os textos indicam que o componente está relacionado com a área de Linguagens, logo, compreendem que o objeto de estudo da Educação Física são os signos, sentidos e significados que os grupos sociais conferem à cultura corporal (ou cultura corporal de movimento). Como é possível observar, a organização dos conteúdos em eixos ou unidades temáticas também seguem uma lógica técnica e aplicacionista. No caso das brincadeiras e jogos, danças e lutas, o critério de categorização é a ampliação dos contextos de localidade, indo do familiar/comunitário até o mundial. Nas temáticas de ginástica, o critério é a intencionalidade da prática; nas práticas de aventura, o critério é o local de ocorrência; por fim, os esportes são tipificados por características internas, baseadas em critérios acríticos (técnicas, regras, gestos ou formas de competição). Novamente, o alinhamento indicado até o momento aparece de forma mais explícita e consistente quando comparamos, lado a lado, os Objetivos de Aprendizagem e Desenvolvimento (SÃO PAULO, 2017) e as Habilidades (BRASIL, 2018).

Quadro 6. Brincadeiras e jogos, $1^{\circ}$ e $2^{\circ}$ anos do Ensino Fundamental

\begin{tabular}{|c|c|}
\hline Currículo da Cidade & BNCC \\
\hline (EF01EF01) Vivenciar/experimentar & (EF12EF01) Experimentar, fruir e recriar \\
diferentes brincadeiras e jogos do contexto & diferentes brincadeiras e jogos da cultura \\
familiar/comunitário, incluindo os de & popular presentes no contexto comunitário \\
matrizes africanas e indígenas, & e regional, reconhecendo e respeitando as \\
\hline
\end{tabular}




\begin{tabular}{|c|c|}
\hline $\begin{array}{l}\text { identificando os elementos comuns a essas } \\
\text { brincadeiras (p. 78). }\end{array}$ & $\begin{array}{l}\text { diferenças individuais de desempenho dos } \\
\text { colegas (p. 226-227). }\end{array}$ \\
\hline $\begin{array}{l}\text { (EF01EF02) Explicar as brincadeiras e } \\
\text { jogos populares do contexto } \\
\text { familiar/comunitário, incluindo os de } \\
\text { matrizes africanas e indígenas, } \\
\text { reconhecendo e valorizando a importância } \\
\text { dessas brincadeiras e jogos para suas } \\
\text { culturas de origem (p. 78). }\end{array}$ & $\begin{array}{l}\text { (EF12EF02) Explicar, por meio de } \\
\text { múltiplas linguagens (corporal, visual, oral } \\
\text { e escrita), as brincadeiras e os jogos } \\
\text { populares do contexto comunitário e } \\
\text { regional, reconhecendo e valorizando a } \\
\text { importância desses jogos e brincadeiras } \\
\text { para suas culturas de origem (p. 226-227). }\end{array}$ \\
\hline $\begin{array}{l}\text { (EF01EF03) Organizar e utilizar } \\
\text { estratégias para resolver desafios de } \\
\text { brincadeiras e jogos do contexto } \\
\text { familiar/comunitário, incluindo os de } \\
\text { matrizes africanas e indígenas, prezando } \\
\text { pelo trabalho coletivo e pelo protagonismo } \\
\text { com base no reconhecimento das } \\
\text { características dessas práticas (p. 78). }\end{array}$ & $\begin{array}{l}\text { (EF12EF03) Planejar e utilizar estratégias } \\
\text { para resolver desafios de brincadeiras e } \\
\text { jogos populares do contexto comunitário e } \\
\text { regional, com base no reconhecimento das } \\
\text { características dessas práticas (p. 226- } \\
\text { 227). }\end{array}$ \\
\hline
\end{tabular}

Fonte: Elaborado pelo autor (2021)

Quadro 7. Esportes de marca e precisão, $1^{\circ}$ e $2^{\circ}$ anos do Ensino Fundamental

\begin{tabular}{|l|l|}
\hline \multicolumn{1}{|c|}{ Currículo da Cidade } & \multicolumn{1}{|c|}{ BNCC } \\
\hline $\begin{array}{l}\text { (EF01EF05) Vivenciar/experimentar } \\
\text { esportes e paradesportos de marca e de } \\
\text { precisão, prezando pelo trabalho coletivo e e } \\
\text { pelo protagonismo e identificando os } \\
\text { elementos comuns a esses esportes (p. 78). }\end{array}$ & $\begin{array}{l}\text { (EF12EF05) Experimentar e fruir, } \\
\text { prezando pelo trabalho coletivo e pelo } \\
\text { marca e de precisão, identificando os } \\
\text { elementos comuns a esses esportes (p. 226- } \\
\text { 227). }\end{array}$ \\
\hline $\begin{array}{l}\text { (EF01EF06) Identificar as normas e regras } \\
\text { dos esportes e paradesportos de marca de de } \\
\text { precisão para assegurar a integridade } \\
\text { própria e a dos demais participantes (p. } \\
\text { 78). }\end{array}$ & $\begin{array}{l}\text { EF12EF06) Discutir a importância da } \\
\text { observação das normas e das regras dos } \\
\text { esportes de marca e de precisão para } \\
\text { assegurar a integridade própria e as dos } \\
\text { demais participantes (p. 226-227). }\end{array}$ \\
\hline
\end{tabular}

Fonte: Elaborado pelo autor (2021)

Quadro 8. Ginástica geral, $1^{\circ}$ e $2^{\circ}$ anos do Ensino Fundamental

\begin{tabular}{|c|c|}
\hline Currículo da Cidade & BNCC \\
\hline $\begin{array}{l}\text { (EF01EF10) Experimentar/vivenciar } \\
\text { diferentes elementos básicos da ginástica } \\
\text { (equilíbrios, saltos, giros, rotações, } \\
\text { acrobacias, com e sem materiais) e da } \\
\text { ginástica geral, de forma individual e em } \\
\text { pequenos grupos, adotando procedimentos } \\
\text { de segurança (p. 79). }\end{array}$ & $\begin{array}{l}\text { (EF12EF07) Experimentar, fruir e } \\
\text { identificar diferentes elementos básicos da } \\
\text { ginástica (equilíbrios, saltos, giros, } \\
\text { rotações, acrobacias, com e sem materiais) } \\
\text { e da ginástica geral, de forma individual e } \\
\text { em pequenos grupos, adotando } \\
\text { procedimentos de segurança (p. 226-227). }\end{array}$ \\
\hline $\begin{array}{l}\text { (EF01EF11) Participar da ginástica geral, } \\
\text { identificando as potencialidades e os } \\
\text { limites do corpo e respeitando as } \\
\text { diferenças individuais e de desempenho } \\
\text { corporal (p. 79). }\end{array}$ & $\begin{array}{l}\text { (EF12EF09) Participar da ginástica geral, } \\
\text { identificando as potencialidades e os } \\
\text { limites do corpo, e respeitando as } \\
\text { diferenças individuais e de desempenho } \\
\text { corporal (p. 226-227). }\end{array}$ \\
\hline
\end{tabular}

Fonte: Elaborado pelo autor (2021) 
Quadro 9. Danças, 1ำ e $2^{\circ}$ anos do ensino fundamental

\begin{tabular}{|c|c|}
\hline Currículo da Cidade & BNCC \\
\hline $\begin{array}{l}\text { (EF01EF19) Experimentar/vivenciar, } \\
\text { corporalmente, as danças socializadas no } \\
\text { grupo de estudantes e reconhecidas em seu } \\
\text { contexto cultural familiar/ } \\
\text { comunitário/regional e midiático (TV, } \\
\text { internet etc.), incluindo os de matrizes } \\
\text { africanas e indígenas (p. 79). }\end{array}$ & $\begin{array}{l}\text { (EF12EF11) Experimentar e fruir } \\
\text { diferentes danças do contexto comunitário } \\
\text { e regional (rodas cantadas, brincadeiras } \\
\text { rítmicas e expressivas), e recriá-las, } \\
\text { respeitando as diferenças individuais e de } \\
\text { desempenho corporal (p. 226-227). }\end{array}$ \\
\hline $\begin{array}{l}\text { (EF01EF21) Reconhecer semelhanças e } \\
\text { diferenças entre as danças e produções } \\
\text { culturais apresentadas pelos colegas e } \\
\text { aquelas pertencentes ao seu patrimônio } \\
\text { cultural familiar (p. 79). }\end{array}$ & $\begin{array}{l}\text { (EF12EF12) Identificar os elementos } \\
\text { constitutivos (ritmo, espaço, gestos) das } \\
\text { danças do contexto comunitário e regional, } \\
\text { valorizando e respeitando as } \\
\text { manifestações de diferentes culturas (p. } \\
\text { 226-227). }\end{array}$ \\
\hline
\end{tabular}

Fonte: Elaborado pelo autor (2021)

Quadro 10. Lutas, $3^{\circ}$ anos do ensino fundamental

\begin{tabular}{|c|c|}
\hline Currículo da Cidade & BNCC \\
\hline $\begin{array}{l}\text { (EF03EF24) Vivenciar/experimentar } \\
\text { diferentes lutas/jogos de oposição do } \\
\text { contexto familiar/comunitário } \\
\text { relacionando as diversidades das } \\
\text { atividades às características do contexto } \\
\text { familiar/comunitário. }\end{array}$ & $\begin{array}{l}\text { (EF35EF13) Experimentar, fruir e recriar } \\
\text { diferentes lutas presentes no contexto } \\
\text { comunitário e regional e lutas de matriz } \\
\text { indígena e africana (p. 229). }\end{array}$ \\
\hline $\begin{array}{l}\text { (EF03EF25) Identificar as diferentes } \\
\text { práticas de lutas no contexto familiar/ } \\
\text { comunitário e ancestral (indígena, africano } \\
\text { e outros), problematizando, por meio da } \\
\text { experiência, os significados atribuídos a } \\
\text { essas práticas corporais. }\end{array}$ & $\begin{array}{l}\text { (EF35EF14) Planejar e utilizar estratégias } \\
\text { básicas das lutas do contexto comunitário e } \\
\text { regional e lutas de matriz indígena e } \\
\text { africana experimentadas, respeitando o } \\
\text { colega como oponente e as normas de } \\
\text { segurança. }\end{array}$ \\
\hline
\end{tabular}

Fonte: Elaborado pelo autor (2021)

Quadro 11. Práticas corporais de aventura, 8o e 9o anos do Ensino Fundamental

\begin{tabular}{|c|c|}
\hline Currículo da Cidade & BNCC \\
\hline $\begin{array}{l}\text { (EF08EF42) Experimentar diferentes } \\
\text { práticas corporais de aventuras na } \\
\text { Natureza (p. 115). }\end{array}$ & $\begin{array}{l}\text { (EF89EF19) Experimentar e fruir } \\
\text { diferentes práticas corporais de aventura } \\
\text { na natureza, valorizando a própria } \\
\text { segurança e integridade física, bem como as } \\
\text { dos demais, respeitando o patrimônio } \\
\text { natural e minimizando os impactos de } \\
\text { degradação ambiental (p. 239). }\end{array}$ \\
\hline $\begin{array}{l}\text { (EF08EF43) Identificar os riscos, formular } \\
\text { estratégias e observar normas de } \\
\text { segurança para superar os desafios na } \\
\text { realização de práticas corporais de } \\
\text { aventuras na natureza (p. 115). }\end{array}$ & $\begin{array}{l}\text { (EF89EF20) Identificar riscos, formular } \\
\text { estratégias e observar normas de } \\
\text { segurança para superar os desafios na } \\
\text { realização de práticas corporais de } \\
\text { aventura na natureza (p. 239). }\end{array}$ \\
\hline $\begin{array}{l}\text { (EF08EF44) Realizar práticas corporais de } \\
\text { aventuras, respeitando o patrimônio }\end{array}$ & $\begin{array}{l}\text { (EF89EF21) Identificar as características } \\
\text { (equipamentos }\end{array}$ \\
\hline
\end{tabular}




\begin{tabular}{|l|l|}
\hline $\begin{array}{l}\text { natural e minimizando os impactos de } \\
\text { degradação ambiental (p. 115). }\end{array}$ & $\begin{array}{l}\text { instrumentos, indumentária, organização) } \\
\text { das práticas corporais de aventura na } \\
\text { natureza, bem como suas transformações } \\
\text { históricas (p. 239). }\end{array}$ \\
\hline $\begin{array}{l}\text { (EF08EF45) Reconhecer e refletir sobre as } \\
\text { características (riscos, instrumentos, } \\
\text { equipamentos de segurança, indumentária, } \\
\text { organização etc.) e tipos de práticas } \\
\text { corporais de aventuras na natureza (p. }\end{array}$ & \\
115). & $\begin{array}{l}\text { (EF08EF46) Compreender criticamente as } \\
\text { transformações históricas das práticas } \\
\text { corporais de aventuras na natureza, bem } \\
\text { como as possibilidades de recriá-las (p. }\end{array}$ \\
115).
\end{tabular}

Fonte: Elaborado pelo autor (2021)

\section{Considerações}

Considerando os contextos sociais, históricos e culturais de produção dos documentos e a rápida substituição/ruptura com os documentos anteriores, versões 1 e 2 (BNCC) e Direitos de Aprendizagem (SÃO PAULO, 2016) explicam a semelhança e o alinhamento total entre os documentos curriculares examinados. As análises evidenciam que as concepções de Educação Física, aprendizagem, conhecimento e desenvolvimento humano são absolutamente alinhadas, quando não, iguais.

Por essa razão, discordamos de Callai, Becker e Sawitzki (2019) quando afirmam que a BNCC é um avanço em matéria de concepções críticas. De outra forma, consideramos um retrocesso suas características tecnicistas, bem como os polêmicos critérios de classificação e tipificação das unidades temáticas, já apontados por Neira (2018), Santos e Brandão (2018) e Silva, Alves e Souza (2020). Aqui, ampliamos tais análises acerca da BNCC (Educação Física), indicando que o documento Currículo da Cidade (SP - Educação Física) reproduz, ipsis litteris, as concepções acríticas e distantes dos conhecimentos produzidos recentemente na área ${ }^{8}$.

Na esteira dessas questões, "grita aos olhos" a regularidade materializada nos enunciados dos Objetivos de Aprendizagem e Desenvolvimento (SÃO PAULO, 2017) e das Habilidades (BRASIL, 2018). A pergunta que fica é: Se as redes estaduais e municipais

\footnotetext{
${ }^{8}$ Em um artigo muito assertivo, Silva, Alves e Souza (2020) afirmam que em 2018 durante a produção do Documento Curricular do Estado do Rio de Janeiro ocorreu o mesmo fenômeno de reprodução da BNCC. Os autores também identificam suas características ligadas à cultura corporal e criticam as noções de educação integral, competências e habilidades.
} 
seguirem o exemplo da Secretaria Municipal de São Paulo (SME-SP), qual a necessidade de investir tempo e dinheiro público na elaboração de outros documentos curriculares que apenas reproduzem o que já existe? Não bastaria adotar integralmente o texto da BNCC?

Por fim, sugerimos que as demais redes de ensino, caso elaborem seus próprios textos curriculares, façam-no com efetiva participação de seus professores, compreendendo que a BNCC não traduz uma verdade final sobre educação no Brasil. Ao contrário, é necessária uma leitura analítica e contextualizada da proposta, avaliando-a de maneira crítica e passível de múltiplas ressignificações.

\section{Referências}

BRANDÃO, Helena. Introdução à análise do discurso. Campinas: Ed. Unicamp, 2004.

BRASIL (BR). [Base Nacional Comum Curricular (2018)]. Ministério da Educação. Base Nacional Comum Curricular. Brasília, 2018.

CALLAI, Ana Nathalia Almeida; BECKER, Eriques Piccolo; SAWITZKI, Rosalvo Luís. Considerações acerca da Educação Física escolar a partir da BNCC. Conexões: Educ. Fís., Esporte e Saúde, Campinas, v. 17, p. 1-16, 2019.

Disponível em:

https://periodicos.sbu.unicamp.br/ojs/index.php/conexoes/article/view/8654739 Acesso em: 12 jan. 2021. https://doi.org/10.20396/conex.v17i0.8654739

FISCHER, Rosa Maria Bueno. A análise do discurso: para além de palavras e coisas. Educação \& Realidade, v. 20, n. 2, p. 18-37, jul./dez. 1995.

FISCHER, Rosa Maria Bueno. Foucault e a análise de discurso em educação. Cadernos de Pesquisa, n. 114, p. 197-223, nov. 2001.

FOUCAULT, Michel. A função política do intelectual. In: MOTTA, Manoel Barros da (org.). Ditos e escritos. Arte, epistemologia, filosofia e história da medicina. Rio de Janeiro: Forense Universitária, 2011. v. 7, p. 213-219.

FOUCAULT, Michel. Microfísica do poder. São Paulo: Graal, 2012.

MENDONÇA FILHO, José. Vídeo Mendonça Filho fala sobre a BNCC em rede nacional (2 min. 34 s). Canal Ministério da Educação. Disponível em: https://www.youtube.com/watch?v=CouiSat5o 8. Acesso em: 2 jul. 2020.

NEIRA, Marcos Garcia. Incoerências e inconsistências da BNCC de Educação Física. Rev. Bras. Ciênc. Esporte, Porto Alegre, v. 40, n. 3, p. 215-223, set. 2018. Disponível em: https://www.scielo.br/scielo.php?script=sci arttext\&pid=S010132892018000300215\&lng=pt\&nrm=iso. Acesso em: 12 jan. 2021. https://doi.org/10.1016/i.rbce.2018.04.001 
RODRIGUES, Denise Simões; MELO, Maria Lúcia. Estudo sobre análise de discurso como procedimento metodológico na pesquisa documental. Revista Educação, Santa Maria, v. 45, 2020. Disponível em: https://periodicos.ufsm.br/reveducacao. Acesso em: 12 jan. 2021. http://dx.doi.org/10.5902/1984644434018

RUFINO; Luiz Gustavo Bonatto; SOUZA NETO; Samuel de. Saberes docentes e formação de professores de Educação Física: análise da Base Nacional Comum Curricular (BNCC) na perspectiva da Profissionalização do Ensino. Motrivivência, v. 28, n. 48, p. 42-60, set. 2016. Disponível em:

https://periodicos.ufsc.br/index.php/motrivivencia/article/view/21758042.2016v28n48p42.

Acesso em: 12 jan. 2021. http://dx.doi.org/10.5007/2175-8042.2016v28n48p42

SANTOS, Marcio Antonio Raiol dos; BRANDÃO, Pedro Paulo Souza. Base Nacional Comum Curricular e currículo da Educação Física: qual o lugar da diversidade cultural? Horizontes, v. 36, n. 1, p. 105-118, jan./abr. 2018. Disponível em: https://revistahorizontes.usf.edu.br/horizontes/article/view/593. Acesso em: 12 jan. 2021. https://doi.org/10.24933/horizontes.v36i1.593

SÃO PAULO (SP). [Direitos de Aprendizagem (2016)] Secretaria Municipal de Educação. Coordenadoria Pedagógica. Divisão de Ensino Fundamental e Médio. Direitos de aprendizagem dos ciclos interdisciplinar e autoral: Educação Física. São Paulo: SME/COPED, 2016.

SÃO PAULO (SP). [Currículo da Cidade (2017)]. Secretaria Municipal de Educação. Coordenadoria Pedagógica. Currículo da Cidade: Ensino Fundamental: Educação Física. São Paulo: SME/COPED, 2017.

SILVA, Amanda Moreira da; ALVES, Marcelo Paraíso; SOUZA, Nádia Maria Pereira de. Educação Física na BNCC: uma análise da proposta preliminar do documento curricular do Estado do Rio de Janeiro. Educação em Revista, Marília, v. 21, n. 2, p. 137-150, 2020. Disponível em:

https://revistas.marilia.unesp.br/index.php/educacaoemrevista/article/view/9881.Ace sso em: 12 jan. 2021. https://doi.org/10.36311/2236-5192.2020.v21n02.10.p137 

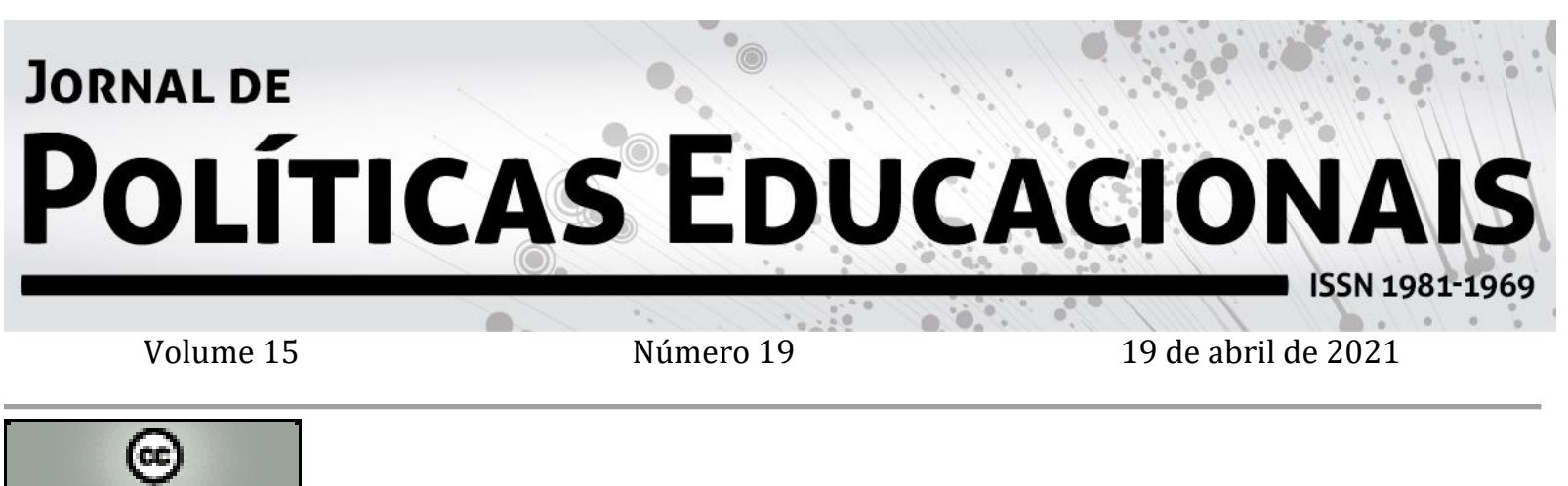

SORE RIGHIS RESERVED O Copyright é retido pelo/a autor/a (ou primeiro co-autor) que outorga o direito da primeira publicação ao Jornal de Políticas Educacionais. Mais informação da licença de Creative Commons encontram-se em http://creativecommons.org/licenses/by-nc-nd/2.5. Qualquer outro uso deve ser aprovado em conjunto pelo/s autor/es e pelo periódico.

JoRnAl DE PolíTICAS EdUCACIONAIS é uma publicação do Núcleo de Políticas Educacionais do Setor de Educação da Universidade Federal do Paraná - NuPE/UFPR, em consórcio com a Linha de Pesquisa em Políticas Educacionais do Programa de Pós-Graduação em Educação - PPGE/UFPR, que aceita colaboração, reservando-se o direito de publicar ou não o material espontaneamente enviado à redação. As colaborações devem ser enviadas ao NuPE/UFPR, conforme orientações contidas nas páginas do periódico na internet: http://revistas.ufpr.br/jpe.

\section{INDEXAÇ̃̃O:}

BASE DE DADOS
Sumário.Org
Google Scholar
BASE
Dimensions
Miar

DIRETÓRIOS
Diadorim
DOAJ
Erih Plus
Latindex
EZB
ROAD
Journal 4-free

\author{
ÍNDICES \\ Index Copernicus \\ Cite Factor \\ PORTAIS \\ LiVre \\ Capes
}

Science Open

Whrld Wide Srienre

(Periódico integralmente disponível apenas em via eletrônica)

Jornal de Políticas Educacionais / Núcleo de Políticas Educacionais da Universidade Federal do Paraná NuPE/UFPR - v.1, n. 1 (1o semestre de 2007) - Curitiba: NuPE/UFPR.

Volume 15, número 19 - Abril de 2021

ISSN 1981-1969

1. Educação - Periódicos. 2. Política Educacional - Periódicos. I. NuPE/UFPR 
Comitê Editorial:

Elisângela Scaff (UFPR)

Daniela de Oliveira Pires (UFPR)

Conselho Editorial:

Andréa Barbosa Gouveia (UFPR - Brasil), Angela Maria Martins (FCC, Brasil), Antonia Almeida Silva (UEFS, Brasil), Cesar Tello (Universidad Nacional Tres Febrero, Argentina), Cristiane Machado (Unicamp- Brasil), Elton Luiz Nardi (UNOESC, Brasil), Fernanda Saforcada (Universidad de Buenos Aires - UBA - Argentina), Gladys Beatriz Barreyro (USP - Brasil), Gilda Cardoso Araújo (UFES - Brasil), Gustavo Enrique Fischman (Arizona State University - USA), Janete Maria Lins de Azevedo (UFPE, Brasil), Jefferson Mainardes (UEPG Brasil), João Ferreira de Oliveira (UFG - Brasil), Jorge Manuel Gorostiaga (UNSAM - Argentina), Juca Gil (UFRGS - Brasil), Luciana Rosa Marques (UFPE, Brasil), Luiz Souza Júnior (UFPB - Brasil), Marcia Aparecida Jacomini (Unifesp-Brasil), Maria Dilnéia Espíndola Fernandes (UFMS, Brasil), Ney Cristina Monteiro de Oliveira (UFPA - Brasil), Nicolás Bentancur, (Universidad de la República de Uruguay), Nora Krawczyk (Unicamp- Brasil), Pedro Flores-Crespo (UAQ, México) Rodrigo da Silva Pereira (UFBA, Brasil), Robert Verhine (UFBA - Brasil), Rosana Cruz (UFPI - Brasil), Rubens Barbosa Camargo (USP - Brasil), Sebastián Donoso Díaz (Universidad de Talca - Chile), Theresa Adrião (UNICAMP - Brasil), Vera Maria Vidal Peroni (UFRGS - Brasil).

Créditos e Agradecimentos:

Revisão de Língua Portuguesa, Abstract e Resumen: Programa de apoio às publicações científicas periódicas da UFPR

Arte e diagramação: Tiago Tavares (tiagotav@gmail.com)

Jornal de Políticas Educacionais

Universidade Federal do Paraná Setor de Educação

Núcleo de Políticas Educacionais - NuPE/UFPR

Avenida Sete de Setembro, 2645

$2^{\circ}$ andar, Sala 213

80.230-010 - Curitiba - PR - Brasil

Tel.: 41-3535-6264

jpe@ufpr.br

http://revistas.ufpr.br/jpe 